\title{
DIÁLOGOS ENTRE O CONCEITO DE EXPERIÊNCIA EM WALTER BENJAMIN E A CLÍNICA DA ATIVIDADE
}

\author{
DIALOGUES BETWEEN THE CONCEPT OF EXPERIENCE IN \\ WALTER BENJAMIN AND THE CLINIC OF ACTIVITY
}

\begin{abstract}
Maria Elizabeth Barros de Barros ${ }_{(0000-0003-1123-4374)^{1}}$, Maria Carolina de Andrade Freitas ${ }_{(0000-}$ 0002-6585-1370)², Suzana Maria Gotardo Chambela ${ }^{3}$
\end{abstract}

\author{
${ }^{1}$ Universidade Federal do Espírito Santo, Departamento de Psicologia, Vitória, Espírito Santo, Brasil. \\ <betebarros@uol.com.br> \\ ${ }^{2}$ Universidade Vila Velha, Departamento de Psicologia, Vila Velha, Espírito Santo, Brasil. \\ ${ }^{3}$ Instituto Federal de Educação, Ciência e Tecnologia do Espírito Santo, Campus Santa Teresa, Espírito \\ Santo, Brasil.
}

Resumo O estudo que deu origem a este artigo, realizado em Vitória (ES) em 2016, teve como objetivo discutir o conceito de experiência na obra de Walter Benjamin e possíveis intercessões com as formulações em Clínica da Atividade. Buscou pensar tais limiares, produzir inflexões no campo das clínicas do trabalho, e com esse objetivo apresentar um leque de questões conceituais e metodológicas com base nas contribuições benjaminianas. O texto se organizou de acordo com conceitos que compõem a Clínica da Atividade, em especial o conceito de atividade, e o modo como essa clínica aborda a questão da experiência. Em seguida, destacou-se o conceito de experiência em Benjamin e buscou-se estabelecer um diálogo entre os conceitos de atividade e experiência nessas abordagens. A análise procurou mostrar a importância dessa confrontação conceitual-metodológica quando a transformação dos mundos do trabalho se apresenta como direção éticopolítica. Concluiu-se que nem o conceito de experiência em Benjamin nem o de atividade em Clínica da Atividade podem ser tomados como da ordem da privatização da experiência humana, indicando a dimensão sempre coletiva dos processos de trabalho.

Palavras-chave atividade; experiência; Clínica da Atividade; saúde do trabalhador.
Abstract The study that originated the present article, which was performed in the city of Vitória, capital of the state of Espírito Santo, Brazil, in 2016, had the goal of discussing the concept of experience in the works of Walter Benjamin and its possible intersections with the formulations of the Clinic of Activity approach. We sought to think of these thresholds to produce turning points in the field of the work clinics, and, with this goal, to present an array of conceptual and methodological questions based on Benjamin's contributions. The text is organized according to the concepts that compose the Clinic of Activity, especially the concept of activity and the way in which this clinic approaches the issue of experience. Subsequently, we highlighted the concept of experience in the works of Benjamin and tried to establish a dialogue between the concepts of activity and experience in these approaches. With the analysis, we tried to show the importance of this conceptual-methodological confrontation when the transformation of the worlds of labor presents itself as an ethical-political directive. We concluded that neither the concept of experience in the works of Benjamin nor the concept of activity within the Clinic of Activity can be understood as part of the privatization of human experience, indicating a dimension of the work processes that is always collective.

Keywords activity; experience; Clinic of Activity; worker's health. 


\section{Introdução}

É bom renovar o espanto da gente, diz o filósofo.

Matilde Campilho (2015)

Em prefácio do livro Trabalho docente e poder de agir: Clínica da Atividade, devires e análises (Barros, Rosemberg e Ronchi Filho, 2014), Yves Clot afirma que, ao ler a obra, percebeu o quanto seu próprio trabalho já havia se tornado outra coisa além de seu próprio trabalho. Clot diz que se deu conta, preparando esse prefácio, de que a Clínica da Atividade ultrapassou fronteiras e se tornou brasileira. Seguiu outros caminhos, diferentes daqueles trilhados na França.

No fim das contas, eu me vi em face a um sentimento muito útil para a atividade científica, um sentimento de estranheza diante de meu próprio trabalho [...]. Um exercício de repetição sem repetição [...]. De tanto passar de mão em mão e de boca a boca a atividade repetida assume uma dimensão genérica que faz 'falar a profissão' entre sujeitos e em cada um deles, contribuindo, assim, para cristalizar a instância do 'destinatário de escapatória' (Clot, 2011, p. 190).

É esse exercício de repetir sem repetir que pretendemos focalizar neste artigo. Produzir estranhamentos naquilo que muitas vezes pode estar acalmado. Atiçar esse sentimento de estranheza tão importante nas pesquisas científicas. Com esse objetivo, apresentamos algumas questões: não seria o conceito de experiência em W. Benjamin um importante intercessor das formulações em Clínica da Atividade? Que limiares pensar entre os conceitos de atividade na Clínica da Atividade e o de experiência em W. Benjamin? Como o conceito de experiência em Benjamin pode ser um intercessor da Clínica da Atividade? Como produzir algumas inflexões no campo das clínicas do trabalho com esse exercício? Como fazê-las serem outra coisa? Afinal, "compreender menos, ser ingênuos, espantar-se, são reações que podem nos levar a enxergar mais, a apreender algo mais profundo" (Ginzburg, 2001, p. 149). O efeito do estranhamento é necessário para resguardar certa leitura da história e pintá-la ao revés.

Tais indagações compõem o leque de nossas questões, visando ao desenvolvimento conceitual e metodológico em clínicas do trabalho, uma vez que nos interessa esse exercício de repetição sem repetição, produzindo inflexões nesse campo que possam intervir nos modos de produção de subjetividade no e pelo trabalho. Uma política que pretende investir na abertura à emergência de novos arranjos existenciais e de novos mundos por meio da expansão do poder de agir (Clot, 2010) ${ }^{1}$ de trabalhadores e trabalhadoras.

Entendemos que há um link fecundo a ser criado entre a proposição de Clot e as construções benjaminianas quanto à experiência. Movido por 
essas indagações, o artigo se estruturou da seguinte forma: apresentação do conceito de atividade na Clínica da Atividade como operação que coloca em análise o trabalho humano; em seguida, o pensamento de Benjamin sobre a questão da experiência; e para finalizar, algumas considerações acerca dos limiares conceituais entre atividade e experiência na Clínica da Atividade e em Benjamin, respectivamente.

\section{Clínica da Atividade: a atividade em análise}

Yves Clot (2010) e seus colaboradores tomam o trabalho do ponto de vista da atividade, ou seja, os caminhos que os trabalhadores percorrem para que as tarefas possam se efetivar. Consideram que existem dois momentos correlativos na atividade. Um deles diz respeito à estrutura instrumental e o outro à sua inserção num sistema de relações entre os humanos. Uma atividade liga os humanos não apenas ao mundo das coisas, mas também a outros humanos. Logo, os trabalhadores nunca estão sozinhos em face do mundo de objetos no curso de sua atividade de trabalho, daí a necessidade de comunicação verbal entre homens e mulheres.

Nessa perspectiva, a atividade é, por meio da realização da tarefa, e também contra ela, produção de um mundo de objetos materiais ou simbólicos, de relações humanas e criação e recriação de mundos. A atividade de um sujeito não seria jamais somente efeito de condições externas, é sempre sede de investimentos vitais. Ela transforma objetos do mundo em meio de viver. Com esse entendimento, Clot (2016) nos indica que a atividade dos sujeitos no trabalho não é determinada mecanicamente por seu contexto, pois a atividade o transforma num processo de coemergência. Ela emancipa, sempre com a possibilidade de falhar, o sujeito das dependências da situação concreta e subordina o contexto em questão.

A atividade é esse processo de subordinação do contexto, é apropriação desse contexto, como também sua produção. Clot (2016) considera que essa domesticação possível ou impossível é específica da espécie humana, que faz de todas as coisas não somente um objeto de troca social, mas, ao mesmo tempo, objeto de uma produção. Podemos dizer, então, que a atividade não existe em um contexto a não ser produzindo-o para existir.

Viver no trabalho é poder desenvolver sua atividade, seus objetos, seus instrumentos, intervindo na organização do trabalho segundo a iniciativa dos trabalhadores. A atividade realizada em situação de trabalho é, frequentemente, o que resta factível quando muito do que é desejável de ser realizado foi descartado.

Se assim é, a atividade não pode ser reduzida ao realizado. A atividade comporta também outra dimensão: o 'real da atividade' (Clot, 2010). Tal di- 
mensão refere-se a um plano de indeterminação prévia, uma resposta singular e situada que os trabalhadores criam em ato de maneira a enfrentar as infinitas variabilidades do meio, que é sempre infiel, como nos indica Canguilhem (2012). Com base nesse autor, Clot afirma (2006, p. 19):

[...] o real da atividade é também tudo o que não se faz, aquilo que não se pode fazer, aquilo que se busca fazer sem conseguir - os fracassos -, aquilo que se teria querido ou podido fazer, aquilo que se pensa ou que se sonha poder fazer alhures. É preciso acrescentar a isso - o que é um paradoxo frequente - aquilo que se faz para não fazer aquilo que se tem que fazer ou ainda aquilo que se faz sem querer fazer. Sem contar aquilo que se tem de refazer.

O trabalho, do ponto de vista da atividade, é tomado como um plano potencial de ação, em que forças de criação são ativadas para que novos modos de fazer singulares (que se expressam no ato de um trabalhador, que não se dissociam do plano coletivo) possam emergir, pois sempre há uma dimensão do trabalho em vias de se atualizar. Atividade implica, mesmo que de forma ínfima, criação de modos novos de trabalhar. Nessa operação, trabalho e trabalhadores são renovados. Os modos de gestão do trabalho, em um movimento incessante de criação, indagam modos instituídos de viver e trabalhar.

Ao se verem confrontados com situações sobre as quais não existem formas preestabelecidas de agir, os trabalhadores se veem forçados a se reinventarem no enfrentamento das situações imprevistas. Clot (2006) afirma que o trabalho carrega uma função psicológica específica, uma vez que, como atividade, transforma e produz mundos e subjetividades. Subjetividade e atividade em permanente processo de coengendramento.

A 'função psicológica do trabalho' consiste, portanto, em possibilitar renovados posicionamentos subjetivos que se efetivam com a transformação do mundo pelos atos 'do' e 'no' trabalho que emergem da atividade em ato, do trabalho vivo. Tal função teria um papel crucial na constituição dos humanos como sujeitos em relação, num processo criacionista em que "o trabalho é uma base que mantém o sujeito no homem, visto que é a atividade mais transpessoal possível" (Clot, 2006, p. 28). Essa função se expressa quando o trabalhador não se percebe mais como fundido com sua tarefa, e o agir tende a aumentar o poder de afetar e ser afetado.

Importante destacar também que, mediante uma leitura espinosana em Clínica da Atividade, entende-se que a subjetividade diz respeito ao poder de ser afetado, não estando o poder de agir separado desse poder de afecção. Os humanos estão sempre repletos de possibilidades não realizadas, as quais constituem um campo de forças baseado no qual o sujeito pode agir, que se refere a uma dimensão virtual do trabalho. É importante, assim, destacar que esse poder não se reduz a fazer coisas ou a realizar tarefas - muito ao 
contrário. Trata-se de criar outras pistas, outros caminhos, de acionar meios para viver, para fazer o trabalho e, nesse processo, operar transformação de si e do trabalho.

Tomar o trabalho como atividade posiciona a questão clínica do trabalho como operação que engendra modos de gerir os processos laborais, modos de subjetivação e mundos outros, com base nas convocações para fazer a gestão da distância entre trabalho prescrito e trabalho real - sempre em análise, portanto. Aqui identificamos uma dimensão da experiência: arranjos que envolvem tanto uma aderência a esferas normativas para trabalhar quanto a criação com base nelas.

\section{Experiência e atividade}

Yves Clot, em artigo publicado em 2011 e intitulado “Clínica do trabalho e Clínica da Atividade", indica que, em seu trabalho, podemos encontrar uma concepção de experiência que se aproxima da formulação de Vygotsky (1999) sobre experiência artística (Clot, 2011). Ele considera que o trabalho, tal como a arte, tem uma potência, uma fonte de alteridade, de inventividade. Assim como a arte, o trabalho pode acessar um plano de forças que é fonte de energia vital, uma vez que o social está em nós e porta, antes de tudo, conflitos. Essa dimensão da experiência diz respeito às disputas de forças no plano social. Conforme o autor, é no encontro de devires que a criação do novo pode ocorrer, escapando das repetições. O trabalho como atividade, como criação de novos possíveis, é produção de transformação de si apoiado no encontro com um plano de forças que nos atravessa e nos constitui. É assim que o novo pode se produzir no trabalho quando está em curso um processo de produção criativa de si mesmo, que se dá na experiência de trabalho, com o que se passa na atividade.

Seguindo Vygotsky (1999), ${ }^{2}$ Clot considera que uma experiência porta a ideia de que uma situação, a princípio objetiva, pode ser interpretada, experimentada ou vivida diferentemente por diversos sujeitos e tem uma característica de transformação, marca uma diferença nos sujeitos nos quais ela se dá. Portanto, uma situação não está dada a priori, ela se constitui num processo que coengendra sujeito e meio de trabalho.

Nas formulações em Clínica da Atividade, a vida se recria na experiência, o que nos remete à concepção de saúde como recriação constante de possibilidades de viver, como defendida por Clot (2010) com base em Canguilhem (2012), que reconhece a atividade como experiência vital, experiência de criação de vida.

Tal experiência não é algo que se dê 'de fora para dentro'; pelo contrário, ela produz seus efeitos exatamente por atravessar sujeitos e contextos. Trata-se de algo que diz respeito a uma relação transversal e não a uma simples troca 
entre instâncias isoladas. Logo, não parte de pontos de partida a priori. Experiência, como ações inacabadas, efetiva-se no fluxo de seu acontecer e, como vivência de finalização incerta, viabilizada pelo real da atividade, precisa ser um meio para viver outras experiências (Clot, 2001). Ou seja, uma experiência deve portar aberturas que sejam férteis para gerar outras novas experiências.

Então o objeto da clínica é a atividade e seus impedimentos, porque a ideia de desenvolvimento da atividade está ligada a poder traçar novos objetivos e experimentá-los. Há, portanto, todo um campo experiencial no qual efetivação e desenvolvimento da atividade são inseparáveis.

Ao se considerar que, no entendimento de Yves Clot (2006), o trabalho realizado e a atividade que se desenvolveu para alcançá-lo não são correspondentes, a Clínica da Atividade busca instrumentos para compreender a situação de trabalho real, valendo-se, para isso, de um modo de pensar que articula atividade e subjetividade. Como já indicado, Clot (2006) considera que o real da atividade sempre é maior do que a atividade realizada. O realizado é uma parte do real. Aqui temos uma articulação entre real da atividade, experiência e criação do novo, pois é nessa possibilidade de abertura para viver novas experiências que o trabalho permite a criação de outras vias para se efetivar. Seguindo essas pistas, podemos afirmar que o trabalho não é apenas dominação e controle.

À Clínica da Atividade interessará, então, compreender as relações entre o real e o realizado e em que condições a experiência vivida pode ser ou vir a ser um meio de viver outras experiências, já que, ao se estudar detalhadamente aquilo que os trabalhadores fazem, aquilo que eles dizem do que fazem, mas também aquilo que eles fazem do que eles dizem, desembocamos em um reconhecimento das possibilidades insuspeitadas pelos próprios trabalhadores (Clot, 2001). Trata-se, portanto, de uma experiência de dimensão eminentemente temporal, de forma que passado, presente e futuro se encontram para seguirem produzindo-se mutuamente. Daí a afirmação de Clot (2001) a respeito da potência de uma experiência como abertura para se fazerem novas experiências. Experienciar algo seria participar de uma realidade que produz algum impacto. Os sujeitos passam por uma experiência de maneira singular, mas sempre condizente com uma história.

Tal como a arte, que seria um meio pelo qual os afetos podem ser transformados, uma "via para viver novos afetos e dar forma ao inacabado" (Clot, 2011 , p. 198), também o trabalho pode se fazer como essa via.

Merece destaque, ainda, o fato de que experiência, em Clínica da Atividade, se refere a uma dimensão que diz respeito a um coletivo que não se encontra cristalizado. Coletivo como um campo de sentidos compartilhados, não encerrados em si mesmos. Nas relações sociais de trabalho, os trabalhadores têm a possibilidade de se produzirem de inúmeras maneiras, de expandir seu viver, produzindo-se por singularidade, de forma coletiva. O conceito 
de experiência liga-se, então, à análise dos dramas e aos conflitos humanos. Conforme Clot (2016) nos adverte, sem o conflito a experiência mingua.

Assim, o poder de agir não está no sujeito isolado; ele o desenvolve na sua atividade com os outros. Ele o retira da ação conjunta entre sujeitos e objetos do mundo real. Portanto, poder de agir desenvolve-se como atividade coletiva. Experiência articulada a uma dimensão coletiva, uma zona não pessoalizada de forças por onde ganham passagem o trabalhador e seu trabalho. Experiência transpessoal criadora, como processo que trata da produção de problemas comuns pelos quais se modificam sujeitos e mundos. Tal direção de análise nos remete a um operador importante em Clínica da Atividade, que é o conceito de gênero profissional. A experiência é tomada como o que é capaz de modificar sujeitos mediante esse patrimônio coletivo.

O conceito de gênero profissional indica uma herança que os trabalhadores acessam para realizar o trabalho (Clot, 2010). Ele tem estabilidade sempre transitória, alimentando-se, permanentemente, das renovações efetivadas pelas estilizações no ato de cada trabalhador. O gênero seria um corpo intermediário entre sujeitos, um interposto social situado entre eles e entre trabalhadores e objeto de trabalho. Tal patrimônio viabiliza singularizações e convoca a uma mobilização subjetiva, que é o estilo, instrumento que pode transformar os gêneros, possibilitando que se mantenham em 'estado de funcionamento', de forma que esses gêneros possam se transformar e se desenvolver (Clot, 2010). O gênero é a condição de antecipação da atividade do outro e da troca social que marca a atividade de trabalho, que seria irrealizável se os sujeitos não utilizassem atividades pré-construídas na história dos gêneros.

Dessa forma, os gêneros se mantêm vivos com a operação das constantes atualizações estilísticas. A possibilidade de os coletivos se manterem em atividade passa por essa estilização dos gêneros que vai se articulando com o plano coletivo por meio de contribuições singulares que, por sua vez, emergem de um coletivo. Coletivo e singularidade como dimensões indissociáveis. Tais processos guardam em si uma potência de contágio, tratam de formulações oriundas de problemas que são produzidos coletivamente e, portanto, compartilhados.

Nessa direção de análise, compartilhamento implica conversa, diálogo. É pela linguagem que as experiências podem 'se processar'. A linguagem é um meio de apropriação e transmissão das experiências, meio pelo qual se possibilita a transmissão. A comunicação, com o objetivo de transmitir projetos, experiências, exige linguagem humana, que advém da demanda de comunicação nos processos de trabalho.

É nas trocas verbais que o novo tem possibilidade de surgir, transformando os sujeitos em meio à relação de diálogo que estabelecem. Clot (2006, p. 26), citando Bakhtin, aponta o diálogo como um procedimento para desvelar um vivido encerrado: “A verbalização é uma atividade do sujeito em si mesma 
e não apenas um meio de acessar outra atividade". Desse modo, cada sujeito tem a possibilidade de reformular sua ação ao se dirigir aos demais nesse movimento dialógico, construindo algo novo. Estar em atividade de diálogo possibilitaria a construção efetiva de novos modos de trabalhar por meio do favorecimento da estilização do gênero profissional, o que pode resultar no fortalecimento da dimensão coletiva do trabalho.

Diálogo como atividade, como produção e transmissão de experiência, como meio de acessar e se fazer certa experiência. Clot (2010) afirma que o ciclo dialógico entre o que os trabalhadores fazem, o que dizem acerca do que fazem e o que fazem do que dizem pode ser uma forma de eclosão de possibilidades insuspeitadas pelos próprios trabalhadores. O diálogo é atividade que transforma a experiência vivida em meio de viver outras experiências. Seria um mecanismo pelo qual ela se torna transmissível e fértil para gerar outras experiências.

Nesse sentido, rastrear um conceito de experiência na Clínica da Atividade não significa, aqui, dizer que tal conceito seja foco nas formulações de Yves Clot, que se interessa, sobretudo, pela concepção de atividade como potência concernente ao trabalho. A ideia de experiência aparece de forma a dar conta de como o desenvolvimento da atividade é possibilitado ao se considerarem os desafios do contexto social e as marcas singulares dos indivíduos. Ao tratar do trabalho como pertencente à ordem da gestão de um meio sempre infiel, Canguilhem (2002) afirma que é nesse tipo de experiência que o sujeito se vê compelido a desenvolver novas maneiras para viver, necessitando sustentar-se em um coletivo, o qual se encontra sempre aberto a constantes contribuições singulares.

Como já indicado, é na experiência artística, com base nas formulações de Vygotsky (1999), que se encontra uma pista para a formulação de um conceito mais amplo de experiência em Clínica da Atividade. Clot (2010) refere-se a certo estranhamento que a arte é capaz de provocar nos sujeitos, algo que impacta sem repelir e traz já consigo o acesso a sentidos dos quais o indivíduo não tinha conhecimento anteriormente. Tais pistas se insinuam à medida que Clot considera a atividade como uma experiência que não apenas se refere a lidar com situações práticas a resolver, mas também diz respeito a dar conta de poder se produzir diferentemente ao ser confrontada com produções de um coletivo no qual o sujeito habita, produzindo diferença.

O trabalho carrega a potência de realização da atividade na medida em que convoca o sujeito a agir criadoramente, a reinventar a si mesmo e ao mundo para dar conta das imprevisibilidades do real. Insistimos: a atividade, como experiência, é abertura para viver novas experiências, um plano no qual é possível um encontro do singular com as forças e sentidos coletivos, que não se dissociam, e uma abertura para que novos sentidos e novas formas de ser se efetivem. 
Nossa proposta é pensar uma clínica do trabalho como experiência que seja crítica. Experiência como experiência de si parece se afigurar nas pistas que Clot (2010) nos deixa. Atividade no bojo da experiência, como processo que se manifesta na vida humana. Como o conceito de experiência em W. Benjamin pode nos ajudar a avançar nessa conversa?

\section{Conceito de experiência em Walter Benjamin}

Encontramos um debate bastante rico sobre o conceito de experiência também em autores como Foucault (1984), Bondía (2002) e Bergson (1984), o que pode nos ajudar a pensar o conceito de experiência em Benjamin com base nas convergências que tais formulações têm com a abordagem benjaminiana.

Foucault teve como objetivo nos seus trabalhos dos últimos vinte anos criar uma história dos diferentes modos pelos quais, em nossa cultura, os seres humanos tornaram-se sujeitos (Foucault, 1984). Com essa meta para suas pesquisas, considerou três modos de transformação dos seres humanos em sujeitos: o primeiro, que intenta atingir o estatuto de ciência, é o saber; o segundo, o poder, objetiva o sujeito em 'práticas divisoras', como, por exemplo, a divisão entre o louco e o são, o doente e o sadio; e o terceiro refere-se ao modo pelo qual um ser humano torna-se um sujeito, em especial com relação à sexualidade -subjetividade (Dreyfus e Rabinow, 1995). É por este último modo que ele situa a análise do conceito de experiência, destacando-a como experiência histórica, uma trama de discursos e práticas por meio dos quais se dá forma àquilo que somos. Essa trama constitui nossa experiência possível em cada lugar e a cada momento. Logo, não se refere a uma experiência em geral, mas a uma experiência concreta, histórica e culturalmente situada.

Assim, nos estudos foucaultianos, a história se efetiva numa análise dos 'jogos de verdade', dos jogos entre o verdadeiro e o falso, por meio dos quais o ser se constitui historicamente como experiência, isto é, como podendo e devendo ser pensado (Foucault, 1984). Entendemos que a ênfase à dimensão histórica da experiência é um ponto convergente com as formulações benjaminianas.

As formulações de Bondía (2002) sobre experiência também dialogam com o pensamento de Benjamin. O autor considera que a experiência é o que nos passa, o que nos acontece, o que nos toca. Não o que se passa, não o que acontece, ou o que toca de forma indefinida, indeterminada, mas o que marca os corpos. Destaca que vivemos uma pobreza de experiência, como também indicou Walter Benjamin. Na modernidade, afirma o autor, a experiência é 
cada vez mais rara, mesmo num mundo em que se passam tantas coisas, uma vez que vivemos em meio a um turbilhão de informações, sem que estas se tornem experiência. Na verdade, a informação se opõe à experiência, é quase uma 'antiexperiência'. Para ele, essa pobreza está relacionada a um excesso de opinião:

[...] o sujeito moderno é um sujeito informado que, além disso, opina. É alguém que tem uma opinião supostamente pessoal e supostamente própria e, às vezes, supostamente crítica sobre tudo o que se passa, sobre tudo aquilo de que tem informação (Bondía, 2002, p. 24).

Essa conjugação informação-opinião Bondía nomeia periodismo, o que destrói a experiência. Quando a informação e a opinião se sacralizam, ocupam o espaço do acontecer, que é movente e intempestivo. Em outras palavras, diríamos que se trata da fabricação e manipulação de sujeitos pelos aparatos da informação e da opinião, assim incapazes de experiência. Ele lembra que Benjamin dizia que o periodismo é o grande dispositivo moderno para a destruição generalizada da experiência. O sujeito da experiência seria um

território de passagem, uma superfície sensível que aquilo que acontece afeta de algum modo, produz afetos, inscreve algumas marcas, deixa alguns vestígios, alguns efeitos. O sujeito da experiência se define não por sua atividade, mas por sua passividade, por sua receptividade, por sua disponibilidade, por sua abertura (Bondía, 2002, p. 25).

Importante destacar que o autor se refere a uma passividade feita de paixão, padecimento, paciência, atenção, como uma receptividade primeira, uma disponibilidade fundamental, uma abertura essencial. O sujeito da experiência é um sujeito 'ex-posto', em 'ex-posição', é um modo de nos 'ex-pormos', com tudo que isso implica em vulnerabilidade e risco. Por isso é incapaz de experiência aquele que se põe, ou se opõe, ou se impõe, ou se propõe, mas não se 'ex-põe' (Bondía, 2002). É incapaz de experiência aquele que nada passa, a quem nada acontece, a quem nada toca. O sujeito da experiência se deixa afetar, se deixa ameaçar e é um sujeito com quem qualquer coisa pode ocorrer. “O sujeito da experiência tem algo desse ser fascinante que se expõe atravessando um espaço indeterminado e perigoso, pondo-se nele à prova e buscando nele sua oportunidade, sua ocasião" (Bondía, 2002, p. 28).

Em Henri Bergson, também encontramos convergências - mas igualmente divergências - com o pensamento de Benjamin. Bergson, assim como Benjamin, critica a maneira por meio da qual a filosofia moderna tradicionalmente considera a experiência, isto é, como associada, apenas, aos sentidos. Distanciase dessa formulação e considera dois tipos de experiência: um se realiza com 
fins utilitários, do qual surgem os conhecimentos que oferecem fundamento aos conceitos racionais necessários à ciência; e o outro se tece com base no próprio movimento do real, do devir contínuo da matéria e do espírito na natureza, o que indica a necessidade incessante de renovação da experiência, pela qual se efetiva o conhecimento e é sua condição primeira.

Desse modo, tanto a filosofia quanto a ciência têm de se libertar do excesso de intelectualismo e experimentar diretamente as coisas (Bergson, 1984). Bergson afasta-se dos universalismos abstratos e simbólicos e destaca a importância da intuição, afirmando a realidade movente e concreta da duração viva das coisas. Só aí cada ser é experimentado e pensado em si mesmo, preservando o que há de próprio e singular em cada um.

Para Benjamin, essa trilha bergsoniana conduz à exclusão da experiência de qualquer ligação com a história: "é a experiência inóspita da época da industrialização" (Benjamin, 1992, p. 105). A perspectiva bergsoniana indicaria uma filosofia da experiência moderna quando não há qualquer relação que transcenda a memória individual. Benjamin não considera que o recurso à presentificação intuitiva seja uma questão de livre escolha, pois uma única memória não pode suportar a experiência na modernidade. As memórias voluntárias, isto é, as que desejamos conscientemente lembrar, não guardam nada da experiência do passado; a consciência estaria associada mais diretamente à vivência (Erlebnis) e não à experiência (Erfahrung). Esta tem a ver, principalmente, com uma memória involuntária.

Norteando-nos pelas formulações benjaminianas, consideramos que o discurso relativo à experiência é hoje, muitas vezes, conclamado por uma versão intimista, que designa a experiência como aquilo que alguém viveu e que possui. Experiência como solilóquios. A experiência não se dá por totalizações; seu caráter inatual é justo o que lhe confere força. Afirma sua vinculação a um fora, como uma incalculável força que a transplanta, um real que não cessa de vir, é impresumível.

Tal análise significaria que no interior daquilo que julgamos individual em uma experiência encontramos um veio político irredutível, que agita outras histórias dentro de certas histórias. Não há história pura, nem desvinculada dos embriões que a teceram. Essa proposição descentra a experiência de um núcleo individual e psicologizante e a encaminha na direção coletiva da vida sinergicamente microscópica e insurgente, em ebulição constante, em reviravoltas e saltos. Didi-Huberman (2011), ao retomar contribuições benjaminianas, considera que a proposição de tempo, mostrada por Benjamin, realça uma temporalidade passante. Uma experiência põe em questão um tempo que não se explicita na cronologia, um tempo-acontecimento, uma porta entreaberta, como alertou Benjamin (1992, 2013). Retomando a afirmação benjaminiana, consideramos que uma história é feita da ruína e afirmada a contrapelo como uma nova forma de experiência e temporalidade. 
Em Benjamin, portanto, o conceito de experiência é menos uma teoria desenvolvida e postulada do que uma busca incessante de definição e retificação crítica. Ainda que Benjamin tenha revisto suas disposições teóricas e epistemológicas, sua coerência ética não foi jamais esquecida. Sua busca levou-o a denunciar e rejeitar sempre que um conceito de experiência se apresentava opressor, estreito ou esvaziado.

Walter Benjamin se atém ao problema da experiência em quatro ensaios: “Experiência", de 1913 (Benjamin, 1992); "Experiência e pobreza”, de 1933 (Benjamin, 2009); “O narrador", de 1936 (Benjamin, 2012); e "Sobre alguns temas baudelarianos", de 1940 (Benjamin, 2015). Nos três primeiros, utiliza sempre o termo Erfahrung, traduzido como 'experiência', embora seus sentidos e usos variem de um texto para o outro. No último, sobre o poeta Charles Baudelaire, o filósofo usa a palavra Erlebnis (vivência) com o objetivo de definir uma qualidade especial de experiência, e é nesse texto, como em nenhum outro, que Benjamin define o que é a experiência (Erfahrung):

Na verdade, experiência é matéria da tradição, tanto na vida privada quanto na coletiva. Forma-se menos com dados isolados e rigorosamente fixados na memória do que com dados acumulados, e com frequência inconscientes, que afluem à memória (Benjamin, 1992, p. 103).

Pela primeira vez em seus escritos, ele realiza a separação entre a experiência rica da tradição, a Erfahrung, e a experiência pobre da modernidade, doravante chamada de vivência, Erlebnis.

Benjamin tenta separar e definir essa nova forma de experiência moderna: a vivência. Apesar de aceitar a expressão Erlebnis como mais precisa para fundamentar o caráter da mudança estrutural na experiência moderna, ele tende a considerar insuficiente apenas o uso de um novo termo, uma vez que ele ainda poderia se referir a um panorama de uma experiência forjada, que não se depreende diretamente da "vida normatizada, desnaturada das massas" (Lima e Batista, 2013, p. 460).

Assim, em Benjamin, falar de experiência, antes de mais nada, significa falar de uma experiência com o mundo moderno e suas transformações. A experiência benjaminiana relaciona-se com aquilo que é passado de geração em geração, aquilo que tem o peso da tradição e que se situa no âmbito da transmissão geracional. Para Benjamin, a experiência é a transmissão de histórias pela narração: ela sempre é comunicada pelos mais velhos aos mais jovens. Entretanto, com o "monstruoso desenvolvimento da técnica" atingimos "uma forma completamente nova de miséria" (Benjamin, 2012, p. 124), a pobreza de experiência. Essa incapacidade de narrar, de transmitir experiência, aparece como um sintoma da modernidade que quer apagar os restos, o residual, aquilo 
do passado que sobra no presente, pois o pensamento moderno, científico, não permite espaço para a dúvida.

Essa discussão em Benjamin (Erfahrung) ganha uma primeira forma no texto "Experiência", quando o autor ataca a noção de experiência como acúmulo de saber, como 'a máscara do adulto' que torna inválidos os saberes e as ações juvenis:

Num de meus primeiros ensaios mobilizei todas as forças rebeldes da juventude contra a palavra 'experiência'. E eis que agora essa palavra tornou-se um elemento de sustentação em muitas de minhas coisas. Apesar disso, permaneci fiel a mim mesmo. Pois o meu ataque cindiu a palavra sem a aniquilar. $\mathrm{O}$ ataque penetrou até o âmago da coisa (Benjamin, 2009, p. 21).

O 'âmago da coisa' a que se refere Benjamin poderíamos explicitá-lo como a composição de um conceito de experiência fundado em práticas coletivas; como uma tradição forjada por saberes partilhados que conferem sentido a uma vida comunitária e só podem ser compreendidos, retomados e transformados nessa mesma inscrição (Gagnebin, 2012, 2013), como conhecimento transmitido entre pessoas e entre gerações (Lima e Baptista, 2013; Ferreira, 2011), como algo que nos vincula ao nosso patrimônio cultural (Benjamin, 2012).

Essa compreensão de Erfahrung, presente nos textos “Experiência e pobreza", de 1933 (Benjamin, 2009), e "O narrador", de 1936 (Benjamin, 2012), se refere àquilo que nos torna comunidade por meio da exigência de se fazer transmissível. Tal noção vem na contramão do que hoje uma prática academicista corriqueiramente nomeia como experiência.

Como nos alerta Agamben (2005, p. 28), a experiência tem sido expropriada dos humanos em suas mais diversas composições, tomada como produto de um único sujeito universal: "o ego cogito cartesiano, a consciência". Essa experiência carece de comprovação e é colocada sob o crivo da verificabilidade. É assim referida a um experimento criado, planejado e executado para a coleta ou produção de dados, o qual permite "traduzir as impressões sensíveis na exatidão de determinações quantitativas e, assim, prever impressões futuras" (Agamben, 2005, p. 26).

A noção benjaminiana de Erfahrung cinde a formulação capitalística de experiência como propriedade de um sujeito privado, um modo íntimo de sentir e agir, uma vivência que se dá no interior psicológico e pode ser referida como 'de' alguém. Não à toa encontramos o já citado termo Erlebnis, outro nome para isso que em nossa língua chamamos também de experiência (Gagnebin, 2012). Ao longo da obra de Benjamin, portanto, encontramos um esforço de retificação crítica em relação ao conceito de experiência, que objetiva não apenas situar historicamente o problema do conhecimento, mas igualmente buscar a verdade da experiência. 
Uma experiência, nesse sentido, refere-se a algo vivo, forte e transmissível. Uma história que perdura consistente, mesmo e por ser insistentemente transformada, em meio ao turbilhão de informações que chegam a nossos olhos e ouvidos e partem deles todos os dias (Benjamin, 2012). Uma presença balbuciante movendo-se por entre ruínas de devastações cotidianas que tendem a constranger a vida. Uma experiência que existe e resiste como prática: a de uma nova relação com o tempo, um possível a se fazer nas rachaduras de modos cristalizados de viver. Efetiva um 'outro tempo' capaz de cindir a linha reta da história oficial, de torcer a métrica que balizou a divisão cronológica em horas, minutos, segundos, milésimos de segundos, capaz de fragmentar as representações espaciais, "responsáveis por uma falsificação que torna impensável a experiência vivida do tempo" (Agamben, 2016, p. 82).

Nos mundos do trabalho, a experiência tem sido pensada, hegemonicamente, de forma que tudo esteja devidamente organizado e encaixado para que toda a jornada de trabalho esteja meticulosamente dividida, sem sobras. Nada fora do lugar. Isso é o que está posto, institucionalizado, descrito, contratado.

Mas não é o único tempo possível no trabalho, nem que se queira. Um outro tempo exige ser inventado nos entremeios desses mesmos cortes. Exige se fazer por um corte, introduzindo um resto necessário a tal ordenamento. Um resto, "aquilo que impede às divisões de serem exaustivas e exclui que as partes e o todo possam coincidir com si mesmas" (Agamben, 2016, p. 72). Tempo que não é nem a linha - representável mas impensável - do tempo cronológico nem o instante - igualmente impensável - do seu fim; é, antes, o tempo operativo que urge no tempo cronológico e o trabalha e transforma, tempo do qual precisamos para fazer findar o tempo: tempo que nos resta.

Trata-se do tempo da ação, da nossa ação neste mundo para fundar um outro mundo. Esse outro mundo é o mesmo mundo profano, "com um pequeno deslocamento, uma ínfima diferença" (Agamben, 2016, p. 87). A diferença, podemos pensar, é a de apreender a nossa autoria na constituição das formas que se encontram, perceber os desvios que a vida impõe ao vetor produzido pela soma de tudo o que nos é contingência. Implica um movimento incessantemente revolucionário contra as opressões cotidianas.

Nessa perspectiva, lembra-nos Agamben (2005, p. 113): a “história da humanidade mostra-se assim como uma história da saúde", o que seu tradutor para o Brasil complementa aludindo ao fato de que saúde é justamente esse movimento de salvação, de conservação da vida. 


\section{Limiares conceituais: atividade em Clot e experiência em Benjamin}

Quando as questões individuais remetem-se às conexões comerciais, políticas e coletivas, muitas outras histórias agitam-se em seu interior, deixando de poder ser consideradas como expressão de uma vida particular autocentrada. Em Walter Benjamin, por exemplo, tratava-se de um estudo da própria infância como uma experiência que diluía, na articulação de uma forma de escrita, a unidade do eu daquele que escrevia. Politicamente, os fragmentos transmitidos pelo narrador são como sementes que mantêm seu poder germinativo para além do tempo cronológico, dependendo dos nexos que os ouvintes consigam reconhecer em suas próprias reminiscências a partir dos perigos com que se confrontem social e politicamente (Ferreira, 2011, p. 131).

A discussão feita por Clot (2013) em "O ofício como operador de saúde" retoma a noção de ofício não como uma designação do passado a respeito das formas de se exercer uma atividade ou tarefa, nem certo regime de trabalho. Relembra a expressão 'fazer o ofício' exatamente no seu duplo sentido: fazer a atividade, quanto fazer/construir o próprio ofício. Na medida em que o fazemos, nós o ultrapassamos. Ou seja, o ofício não é apenas uma prática, nem apenas diz respeito a uma profissão; é discordância criativa. Algo que se mistura ao nosso contar uma história, uma impressão, uma experiência. Embrenha-se numa narração, deixa as marcas daquilo que não se sabe, mas se transmite (Benjamin, 2012). Uma narrativa, lembra-nos Benjamin (1992), não é composta apenas por aquilo que nela se oraliza, mas também por gestos que se imprimem na maneira como se conta algo, ressaltando o valor do corpo em uso e das mãos que trabalham enquanto se tecem a voz e os fios narrativos, como a argila nas mãos do oleiro.

A análise de Benjamin se articula, para nós, na proposição política na qual insistimos: a vida humana como produção de um ethos comum, inegavelmente colocado em termos éticos e agonísticos. Se o devir não pertence à História, mas às histórias, aos movimentos dos restos, rastros e indícios deixados pelas operações do Real. As transformações da narração nos desafiam a compor outras políticas de narratividade, nas quais insistimos em, apoiados nas ruínas, dos pedaços, dos trapos e fragmentos, rejuntar em recriação, longa e paciente, outras formas de contar as histórias, fazendo-as vazar do molde reinante por escapes insuspeitos.

Conforme nos lembra Gagnebin (1993, p. 67), a narrativa implica "não escamotear as rachaduras, as fraturas, as esquizos de que o mundo sofre, mesmo que só se possa falar delas, mas não repará-las". Nós nos forjamos com base na referencialidade de nossos campos de fazer. Principalmente quando 
nosso fazer, como nos sugerem Pagni e Gelamo (2010, p. 24), “interpela o habitualmente pensado".

Assim, o trabalho opera em todo um processo de realização, torna-se experiência, inclui toda uma gama de acontecimentos conectados e modos de vida e existência. A experiência como criação apontar-nos-ia a capacidade do vivo em transmutar-se pelos encontros e desencontros experimentados nas partilhas da vida em comum, seja pelo encontro com as palavras e o que fica fora delas, seja pelos encontros com as coisas, com algo que nos toque, seja pela produção de gestos na abertura com a pura diferença.

Experiência, como compartilhamento público, aponta para o caráter político da comunhão entre humanos. A transmissão, então, não se afirma como troca de informações ou do repasse delas a outro. Transmissão aqui se vincula à ideia de que algo germina. Um indecidível espreita passagens subterrâneas, ou, como nos diria Batista (2018), efetua-se certa experiência labiríntica na produção dos percursos. E isso porta a extensão no tempo e as atualizações possíveis, pela via das intensidades, das forças e das pulsações. Pulsar não é seguir reto, em sentido linear; pulsar é articular presença e ausência, aproximação e distância. É agitar movimentos, expansões e retrações, contornos imprecisos e saltos improváveis. Pulsar é bifurcar, desviar, embaralhar-se, seguir ziguezagueante numa zona de improvisação viva e vibrátil, enérgica e movediça.

Sugere-nos Caiafa (2000, p. 18) que "é preciso um lapso de tempo para que a experiência se dê. E é na dimensão da experiência que o desejo se inscreve, assim como a criação poética". Aponta-nos a autora que o desejo precisa da distância no tempo e que o gesto brusco tão pertinente aos modos de vida implementados no capitalismo tende a esgotar o instante oportuno no imediatismo do consumo, o que concorre, conforme mostrou Benjamin (1992), para a desqualificação da experiência. Os restos transmitem-se. Pelas frestas dos totalitarismos, por meio de limiares, passagens se efetuam, não cessam de acontecer.

$\mathrm{O}$ indicado por Benjamin significa para nós afirmar que aquilo que se narra, que o trabalhador narra, o que se passa nos diálogos sobre o trabalho, implica não somente considerar as necessárias modificações das condições concretas do trabalho mas também os elementos infraestruturais. Importante considerar, ainda, os modos pelos quais nos articulamos e empreendemos a experiência de tudo isso no esforço de viver e saber, por meio do trabalho da memória, com nossas reminiscências e nossa rememoração, aquilo que nos atingiu, trespassou-nos.

O que os trabalhadores contam sobre as situações de trabalho guarda elementos que o ultrapassam, no sentido estritamente individual, e indica que certos 'gestos' vêm de longe. 
A reminiscência [...] remete-se à defesa de uma experiência com o passado em que se quebra a unidade do sujeito do conhecimento postado, de forma idealizada, sobre o fluxo do tempo. A reminiscência apropriada remete à repetição na história e ao fato de que o sofrimento do passado ainda é o sofrimento do presente (Ferreira, 2011, p. 131).

Essa afirmação nos remete a considerar, como situa Didi-Huberman (2016, p. 32), que, mesmo participando de outro tempo e contexto, há algo que nos acompanha: as emoções, que passam por gestos que fazemos sem nos dar conta e que nos ligam a outra temporalidade: “esses gestos são como fósseis em movimento. Eles têm uma história muito longa - e inconsciente. Eles sobrevivem em nós, ainda que sejamos incapazes de observá-los em nós mesmos". Assim, essas emoções passam.

Elas precisam 'passar'. São uma linguagem. Criam 'impasses', como sugere o autor; não somente criam as dificuldades que pressentimos quando as experimentamos (impasse como aquilo que não passa nos afeta), como se constituem como passagens (im-passes, em passagem). A emoção que o gesto traz é também um impasse da linguagem, do pensamento, da ação. Como transmitir um gesto?

Clot (2010) considera que a aprendizagem do gesto e de seus acasos está ali para nos lembrar que o gesto não deve ser, apenas, mais bem compreendido, ou mais bem sucedido. Só existe técnica e transmissão se existir tradição.

Benjamin (2012) considera que a tradição não pode ser um baú de pertencimentos, mas, antes, um certo depois. A tradição não arruma nada. Ela, antes, trai. Ela pode dizer-se apenas em certo depois, não por ante-existir, mas por produzir-se em apropriações posteriores. Por que isso? Porque a vida salta. Não corre engendrada apenas por continuidade linear. Ela deriva. Rasga. Fissura. Ela almeja. Rompe. Salta. Há quebra. Embaraço. É por derivar que podemos algo. Que insistimos. Que ousamos. O que dura e o que se distancia em movimentos dão saltos.

Transmissão que advém de uma tradição, remete-nos a difusão, propagação e transferência. Para Clot (2010), transmitir um gesto bem-sucedido é transmiti-lo firmemente. Incorporado por quem o realiza, efetiva-se por corporificação do aprendizado. Não se reduz à sua dimensão racional-cognitiva. É um cognitivismo de outra ordem que se dá por acoplamento, dispensa a mediação da representação. É nesse processo de corporificação que é possível expurgar os gestos saturados pelas intenções de outro a fim de conseguir fazê-los de cada um, em situações singulares.

Não é mera imitação. A transmissão do gesto não se faz como uma linha reta que conduz diretamente um sujeito para um objeto; implica apropriação. Uma multiplicidade de modos de fazer pode se configurar, indicando um porvir possível. A transmissão do gesto segue sempre um curioso percurso. 
O que é transmitido é um gesto despertado do sono genérico pela atividade contrariada de um profissional. A transmissão é um desenvolvimento do gesto (Clot, 2010). ${ }^{3}$

Seu sentido não é transparente. A imitação formal do gesto não é uma garantia contra seu uso inadequado. É a partir de uma postura atencional ao presente que vai sendo burilado o que é transmitido, produzindo-se um estilo. Estilizam-se os gestos segundo uma tradição genérica. Aprender um gesto é retocá-lo continuamente em função de circunstâncias sempre heterogêneas que ele atravessa e no âmago das quais ele se refrata e sai enriquecido, mas também eventualmente amputado.

Como fazer seu um gesto alheio? É preciso avaliar se o gesto é apropriado para si próprio em situações concretas e singulares. “O gesto não é uma bola que se passa" (Clot, 2010, p. 163). A experiência coletiva não é transmitida, no sentido de ensinar para o outro o que fazer. Ela resiste e perdura sob a forma de um processo ininterrupto e também pode perder-se. Ninguém recebe uma experiência pronta a ser usada, toma-se lugar na corrente das atividades e dos gestos, que podem produzir uma suspensão temporária. A imobilização de um segundo. O fio de um pavio. Um lampejo. Uma franca força, uma chispa, que atua como um arco, "atinge o instante bem no coração" (Benjamin, 2009, p. 502). Como nos lembra Benjamin (2009), é preciso atentarmos para o exercício de um olhar estereoscópico e dimensional para a profundidade das sombras históricas.

O gesto compõe nossas narrativas. Narramos, em nosso caso, em situações de trabalho, não somente com palavras, mas com as mãos, com um corpo também. O gesto pode ser, simultaneamente, testemunha e testemunhado. Ele pode compor aquilo que a testemunha narra, aquilo que faz ao narrar e aquilo que sofre narrando.

Ao mesmo tempo, o gesto pede que seja testemunhado para que sua existência seja transmissível, pois uma 'emoção', um 'gesto ativo', que não se dirigisse a ninguém, que fosse absolutamente solitário e incompreendido, não se constituiria como 'moção', movimento, e seria "somente uma espécie de cisto morto dentro de nós mesmos" (Didi-Huberman, 2016, p. 33).

A história de um trabalhador não é somente uma história 'dele', de pertença a uma interioridade absoluta. Adverte-nos Didi-Huberman (2016) de que nossas emoções são gestos ativos, que nos lançam para 'fora' de nós mesmos. Elas, portanto, podem consistir num limiar entre o interior e o exterior. Conclui o autor que a emoção não diz 'eu', pois estamos fora de nós mesmos, mas é preciso recorrer à terceira pessoa, como um 'ele' (Didi-Huberman, 2016).

Podemos testemunhar: 'ele sofre'. E reconhecer em nós mesmos, também, algo do movente do mundo. Quando diante de uma imagem, uma narrativa, um gesto, ligamo-nos ao fora de nós. 
Sempre se assume um determinado lugar no curso de atividade. Um gesto está mergulhado nos processos de compartilhamento e sofre intervenção dos conflitos e tensionamentos inerentes ao trabalho humano. Nesse processo vão se viabilizando criações estilísticas, uma vez que coletivo e sujeito não se dissociam.

Então, como transmitir um gesto como tradição? Como operar com um modo de transmissão da experiência em atividade de trabalho? Questões que não perspectivam respostas definitivas, mas são um convite a um exercício, exercício esse que afirma a vida em sua grandeza, o que significa tomá-la como potência em expansão, encarando-a como um modo de sair da dominação do posto e como tarefa imperiosa de ultrapassamento da sobrevivência. "Não somos adaptados a viver um contexto já dado. Somos feitos para fabricar novos contextos" (Clot, 2013, p. 5).

Para tanto, o coletivo nessa proposta não significa agrupamento, ou instituição qualquer. Remete-nos à nossa irredutível dimensão de existência comum e política, na qual podemos afirmar a impossibilidade de existirmos sós. Coletivo não se refere a uma "comunidade protegida" (Clot, 2013, p. 8), tampouco a um 'pertencimento' sacrossanto a uma fila indiana de um agrupamento humano com 'boas práticas'. Coletivo não é um retorno à idade de ouro, de corporação do ofício, que ficou para trás (Clot, 2013).

Coletivo, nessa proposta, conecta-se com aquilo que podemos sem dúvida colocar em partilha, mas que se situa, melhor ainda, naquilo que podemos e até então não sabemos exatamente que podemos. Coletivo que se entrecruza no entrecampo da experiência pessoal, interpessoal, transpessoal e impessoal. Numa força ou, nas palavras de Clot (2013, p. 9), numa "vitalidade deliberada" que assume o trabalho real nas situações concretas de trabalho e vida. Essa vitalidade construída é, segundo enfatiza o autor, verdadeiramente uma dimensão instituinte.

Mas ela é instituinte por razões sociais um pouco diferentes daquelas que habitualmente são apresentadas. Esse 'social' é de fato muito psicológico: na verdade, a 'disputa profissional' faz passar o coletivo no interior de cada profissional em quem essa 'disputa' se dá, queira ele ou não. Assim, não apenas a pessoa está em um coletivo, o coletivo passa pela pessoa. Ele se converte em diálogo interior a serviço de sua atividade própria, teclado coletivo para poder lidar sozinho com a situação, amplitude de opções na qual pode tocar sua própria música singular. Podemos falar de diapasão coletivo para a atividade pessoal. Esse ponto, em geral, é subestimado. O coletivo do qual falamos permite a cada um 'tomar liberdades' com ele, nos vários sentidos da palavra. Nos dilemas do trabalho concreto, um coletivo que toma essa referência sempre incompleta, sempre em debate, obriga cada um a se determinar. A se tornar um pouco mais único em seu gênero, mais singular no seu trabalho. Queremos, então, falar de um coletivo que deixa a desejar. Esse co- 
letivo não é apenas um 'pertencimento' a adotar, mas um instrumento de trabalho pessoal, para usar e cuidar em conjunto (Clot, 2013, p. 9; destaques no original).

Nessa brecha da linguagem, não se enfatiza o sentido restritor da expressão - o que faltou e, por isso, estaria incompleto ou restaria sem valor - mas, ao contrário, o que deixa a desejar. Clot indica que um trabalho mantém sua capacidade viva de se ampliar caso se paute em construção partilhada, em instrumento de ligação, quando, então, é possível apropriar-se do próprio pensamento e agir (Clot, 2010, 2013).

\section{Considerações finais}

Nas trilhas abertas pelas questões entrelaçadas até aqui, retomamos a história (plano da experiência) não somente como aquilo que se vê ou de que se fala, mas também como compartilhamento, modo de lidar com os diversos sentidos produzidos pelos encontros humanos e afirmar uma linha de porvir. Há algo que se presentifica diante da reunião dos humanos e em suas partilhas: algo que escapa, transita, bifurca, desvia, se abre. Essas são indicações que as formulações em Clínica da Atividade e o conceito de experiência nas obras de Benjamin nos ajudam a pensar. Ambos dizem respeito a algo que ultrapassa os sujeitos, algo imprevisível e, especialmente, não privatista. Nem o conceito de experiência em Benjamin nem o de atividade em Clínica da Atividade são tomados como da ordem do privado. Remetem-nos ao acesso de uma dimensão informe e processual.

Como destacamos, em "O narrador" Benjamin alerta-nos para nossa pobreza de experiências, indicando a importância de uma partilha de intensidades impessoais que tecem os fios de uma cultura. Em "Experiência e pobreza", situa justamente essa pobreza como um plano possível para a construção de novas formas de estar no mundo. Ainda em "Experiência e pobreza", assinala, curiosamente, que se os documentos de cultura constituíram-se em documentos de barbárie, uma vez que evidenciaram a história dos vencedores, importa-nos produzir uma inversão desses códigos e afirmar uma dimensão positiva da barbárie, no sentido de que bárbaro é aquele que abre novos caminhos com pouco, com muito pouco. Afirmamos assim, com Benjamin, uma experiência a ser forjada com esse 'pouco' que nos resta como possível, por meio de uma atividade narrativa. Narração que se faz sobre as histórias ordinárias, relegadas, esquecidas; aquela que mergulha na vida para aí ver algo de novo, combinando variados elementos.

Gagnebin (2011) aponta que as indicações de Benjamin em torno da narrativa forçam a ampliação, ao mesmo tempo, política e filosófico-psicológica do conceito de sujeito, o que, por sua vez, tensiona, como já mencionado, o 
modo de pensar a nossa prática histórica, isto é, como contamos nossa história e como agimos nela. Essa concepção auxilia-nos a evitar tanto as armadilhas de um individualismo triunfante quanto as ilusões de uma consciência soberana. A autora interpreta, segundo Benjamin, que contar e lembrar é surpreender-se com a capacidade infinita de interpolação daquilo que foi, efeito da obra secreta da lembrança. Somos atravessados por ondas de desejos, revoltas, desesperos coletivos. O 'eu' não é o sujeito. Portanto, a narração não é fruto de um 'eu', mas da densidade de uma memória pessoal e coletiva. Essa dispersão vertiginosa e criadora do sujeito narrativo, de acordo com a autora, transforma radicalmente nossa visão de autobiografia, pois "o autos não é mais o mesmo, o bios explode em várias vidas que se entrecruzam e a grafia segue o entrelaçamento de diversos tempos que não são ordenados por nenhuma linearidade exclusiva" (Gagnebin, 2011, p. 78).

Tal pensamento concorre para a afirmação de que assim como a noção de atividade não se reporta a algo realizado, mas implica movimentações microscópicas e até mesmo aquilo que não se realiza objetivamente, a noção de experiência em Benjamin afirma essa mesma direção, uma vez que não se reduz ao ponto de vista privatista. Os dois conceitos caminham numa direção comum, que é a de não seguir uma ordem de privatização da experiência humana. Tal dimensão recoloca o debate sobre o trabalho humano e contribui para que o pensemos como uma atividade a contrapelo, coletiva, já que em sua realização torna-se necessário voltar-se não às regularidades, mas aos desvios, às descontinuidades, fazendo-o diferir e tornar-se discordância criativa.

A discussão apresentada buscou estabelecer um diálogo entre a abordagem benjaminiana de experiência e o conceito de atividade em Clínica da Atividade. Tal embate nos trouxe elementos importantes para um reposicionamento nas metodologias em clínicas do trabalho, enriquecendo-as, na medida em que o conceito de experiência em Benjamin se mostrou como um intercessor importante nessa conversa, entendendo que intercessor é o que produz inflexão nos modos habituais de funcionamento, é o que produz quebra no que está dado e, muitas vezes, enrijecido. Com o tear entre essas diferentes linhas que se encontram num ponto de resistência aos processos de privatização da experiência humana, buscamos afirmar o investimento em metodologias que impliquem exercícios de coletivização, trazendo a um plano de visibilidade a dimensão fundamentalmente coletiva da vida e, por conseguinte, do trabalho.

\section{Colaboradoras}

Todas as autoras colaboraram igualmente na elaboração do artigo e não há conflitos de interesses. 


\section{Financiamento}

O artigo baseou-se nas teses de doutorado de duas das autoras: "Nos limiares do fora: Experiência e narratividade em políticas de saúde e educação", de Maria Carolina de Andrade Freitas e "Narrar em nosso tempo: experiência e saúde no trabalho em educação", de Suzana Maria Gotardo Chambela. Ambas as teses foram defendidas no Programa de Pós-Graduação em Educação da Universidade Federal do Espírito Santo, no ano de 2018. O apoio financeiro da Coordenação de Aperfeiçoamento de Pessoal de Nível Superior (Capes) se efetivou por meio de bolsa de estudos.

\section{DIÁLOGOS ENTRE EL CONCEPTO DE EXPERIENCIA EN WALTER BENJAMIN Y LA CLÍNICA DE LA ACTIVIDAD}

Resumen El estudio que sirvió como origen para este artículo, realizado en Vitória (Brasil) en el 2016, tuvo como objetivo discutir el concepto de experiencia en la obra de Walter Benjamin y posibles intercesiones con las formulaciones en Clínica de la Actividad. Se buscó pensar tales umbrales, producir inflexiones en el campo de las clínicas del trabajo, y con este objetivo presentar un abanico de cuestiones conceptuales y metodológicas con base en las contribuciones benjaminianas. El texto se organizó de acuerdo con conceptos que componen la Clínica de la Actividad, en especial el concepto de actividad y el modo como esta clínica aborda la cuestión de la experiencia. A continuación se destacó el concepto de experiencia en Benjamin y se buscó establecer un diálogo entre los conceptos de actividad y experiencia en estos abordajes. El análisis buscó mostrar la importancia de esta confrontación conceptual-metodológica cuando la transformación de los mundos del trabajo se presenta como dirección ético-política. Se concluyó que ni el concepto de experiencia en Benjamin ni el de actividad en Clínica de la Actividad pueden tomarse desde el orden de la privatización de la experiencia humana, indicando la dimensión siempre colectiva de los procesos de trabajo.

Palabras clave salud del trabajador; Organización Internacional del Trabajo; análisis del discurso; salud pública. 


\section{Notas}

${ }^{1}$ Com base no pensamento de Spinosa, Clot (2013) considera saúde como possibilidade de expansão da potência de agir. Não se trata de poder no sentido de fazer coisas, mas poder relativo ao caráter criador dos vivos que estão sempre a inventar e reinventar mundos e viabilizar que sejam o que não eram pela afecção entre corpos. Afetos seriam os estados corporais que aumentam ou diminuem as possibilidades de um corpo com relação à ação, favorecendo-a ou restringindo-a.

${ }^{2}$ Clot (2010) parte do conceito de experiência em Vygotsky (em russo, perejivânie), traduzido nas versões de sua obra em português como vivência.

${ }^{3}$ Para Clot (2006), o conceito de desenvolvimento não está relacionado com um processo evolutivo e hierárquico; refere-se a um processo dinâmico que acompanha o que se cria num processo histórico de um coletivo de trabalhadores.

\section{Referências}

AGAMBEN, Giorgio. Infância e história: destruição da experiência e origem da história. Belo Horizonte: Editora UFMG, 2005.

AGAMBEN, Giorgio. O tempo que resta: um comentário à Carta aos Romanos. Belo Horizonte: Autêntica, 2016.

BARROS, Maria E. B. B.; ROSEMBERG, Dulcinea; RONCHI FILHO, Jair (orgs.). Trabalho docente e poder de agir: Clínica da Atividade, devires e análises. Vitória: Edufes, 2014.

BATISTA, Ruth. Por uma politica de limiar e programa vazio na socioeducação: corpos-narrativas em evasão, 2018. 245f. Tese (Doutorado em Políticas e Formação Humana) - Departamento de Pós-Graduação em Políticas e Formação Humana da Universidade do Estado do Rio de Janeiro, Rio de Janeiro, 2018.

BENJAMIN, Walter. Sobre arte, técnica, linguagem e política. Lisboa: Relógio d'Água Editores, 1992.

BENJAMIN, Walter. Rua de mão única. São Paulo: Brasiliense, 2009.
BENJAMIN, Walter. Magia e técnica, arte e politica: ensaios sobre literatura e história da cultura. 8. ed. São Paulo: Brasiliense, 2012.

BENJAMIN, Walter. Baudelaire e a modernidade. Belo Horizonte: Autêntica, 2015.

BERGSON, Henry. Textos escolhidos. São Paulo: Abril Cultural, 1984.

BONDÍA, Jorge L. Notas sobre a experiência e o saber de experiência. Revista Brasileira de Educação, Rio de Janeiro, n. 19, p. 20-28, jan.- abr. 2002.

CAIAFA, Janice. Nosso século XXI: notas sobre arte, técnica e poderes. Rio de Janeiro: Relume Dumará, 2000.

CAMPILHO, Matilde. Jóquei. São Paulo: Editora 34, 2015.

CANGUILHEM, Georges. Estudos de história e de filosofia das ciências: concernentes aos vivos e à vida. Rio de Janeiro: Forense, 2002.

CANGUILHEM, Georges. O conhecimento da vida. Rio de Janeiro: Forense, 2012. 
CHAMBELA, Suzana M. G. Narrar em nosso tempo: experiência e saúde no trabalho em educação, 2018. 120 f. Tese (Doutorado em Educação) - Universidade Federal do Espírito Santo, Vitória, 2018.

CLOT, Yves. Clinique du travail, clinique du réel. Le Journal des Psychologues, Paris, n. 185, p. 48-51, 2001.

CLOT, Yves. Vygotsky: para além da psicologia cognitiva. Pro-Posições, Campinas, v. 17, n. 2, p. 19-30, 2006.

CLOT, Yves. Trabalho e poder de agir. Belo Horizonte: Fabrefactum, 2010.

CLOT, Yves. Clínica do trabalho e Clínica da Atividade. In: BENASSOLI, Pedro F.; SOBOL, Lis A. (orgs.). Clínicas do trabalho: novas perspectivas para compreensão do trabalho na atualidade. São Paulo: Atlas, 2011, p. 188-207.

CLOT, Yves. O ofício como operador de saúde. Cadernos de Psicologia Social do Trabalho, São Paulo, v. 16, n. spe. 1, p. 1-11, 2013.

CLOT, Yves. Activité, affect: sources et ressources du rapport social. In: DUJARIER, Marie A. et al. (eds.). L'activité en théories: regards croisés sur le travail. Toulouse: Octarès, 2016. p. 51-80.

DIDI-HUBERMAN, George. A sobrevivência dos vaga-lumes. Belo Horizonte: Editora UFMG, 2011.

DIDI-HUBERMAN, George. Que emoção! Que emoção? São Paulo: Editora 34, 2016.

DREYFUS, Hubert L.; RABINOW, Paul. Michel Foucault, uma trajetória filosófica: para além do estruturalismo e da hermenêutica. Rio de Janeiro: Forense Universitária, 1995.
FERREIRA, Marcelo S. Walter Benjamin e a questão das narratividades. Mnemosine, Rio de Janeiro, v. 7, n. 2, p. 121-133, 2011.

FOUCAULT, Michel. História da sexualidade: o uso dos prazeres. Rio de Janeiro: Graal, 1984.

FREITAS, Maria C. A. Nos limiares do fora: experiência e narratividade em políticas de saúde e educação, 2018. 306 f. Tese (Doutorado em Educação) - Universidade Federal do Espírito Santo, 2018.

GAGNEBIN, Jeanne M. Walter Benjamin: os cacos da história. São Paulo: Brasiliense, 1993.

GAGNEBIN, Jeanne M. Limiar, aura $e$ rememoração: ensaios sobre Walter Benjamin. São Paulo: Editora 34, 2011.

GAGNEBIN, Jeanne M. Prefácio: Walter Benjamin ou a história aberta. In: BENJAMIN, Walter. Magia e técnica, arte e política: ensaios sobre literatura e história da cultura. Tradução Sérgio Paulo Rouanet. 8. ed. São Paulo: Brasiliense, 2012. (Obras Escolhidas, v. 1.)

GAGNEBIN, Jeanne M. História e narração em Walter Benjamin. São Paulo: Perspectiva, 2013.

GINZBURG, Carlo. Sinais: raízes de um paradigma indiciário. In: GINZBURG, Carlo. Mitos, emblemas, sinais: morfologia e história. 2. ed. São Paulo: Companhia das Letras, 2001. p. 143-179.

LIMA, João G.; BAPTISTA, Luiz A. Itinerário do conceito de experiência na obra de Walter Benjamin. Principios: Revista de Filosofia, Natal, v. 20, n. 33, p. 449-484, jan.-jun. 2013.

PAGNI, Pedro A.; GELAMO, Rodrigo P. Experiência, educação e contemporaneidade. São Paulo: Poiesis Editora, 2010.

VYGOTSKY, Lev S. A formação social da mente. São Paulo: Martins Fontes, 1999. 